\title{
Environmental problems of the city of Kemerovo and new methods of solving them
}

\author{
Aleksandr Solovitskiy ${ }^{1, *}$ and Nikolai Nikulin ${ }^{1}$ \\ ${ }^{1}$ Kemerovo State University, 6, Krasnaya Str., 650000, Kemerovo, Russia
}

\begin{abstract}
A generalization of the experience of the regional land management of the city of Kemerovo was carried out, and the environmental problems solved in this case were identified, among which the main problem is road transport - the main air pollutant. The purpose of the study is to develop a solution to the environmental problems of the city of Kemerovo by methods of regional land management. The object of the study is the environmental problems of the city of Kemerovo, and its subject is the peculiarities of their solution by methods of regional land management. The studies provide for the development of new solutions for the implementation of the regional land management of the city of Kemerovo based on the formation of a new methodological approach to regulate the traffic flow in order to reduce air pollution. The practical significance of the implementation of the new approach consists in carrying out the regional land management of the city of Kemerovo in order to reduce the impact of emissions from road transport.
\end{abstract}

\section{Introduction}

In the process of research, based on the analysis of literary sources carried out by the author [1-17], it was revealed that in modern conditions, a problematic situation has developed in the Kemerovo area: between the advanced technological capabilities of measuring instruments for air, water and earth surface pollution and the practical absence of full-fledged theoretical developments in the field of obtaining, collecting, registering, processing, and analyzing information on its ecological condition. Therefore, it is required to develop new methods for solving environmental problems. At the suggestion of the author, one of such methods is regional land management [17].

As a method for solving environmental problems, regional land management is poorly covered in the open sources. Let's consider its application in the conditions of the city of Kemerovo.

Kemerovo is a large industrial, administrative and cultural center of the Kemerovo region, which is located on both banks of the Tom River in the center of the Kuznetsk Basin. Its historical basin position determines the increased potential for atmospheric pollution. There are 19,325 business entities registered in the city. Their activity in combination with natural factors determines the ecological situation. The influence of

\footnotetext{
*Corresponding author: san.mdig@mail.ru
} 
natural factors is as follows. Wind currents in the surface layer of the atmosphere are oriented along the valley of the Tom River, but taking into account the relief, they turn to the south and south-west, covering the right-bank recreation area with harmful impurities. Dust pollution and fogging periodically reduce the transparency of the atmosphere, which causes a general deficiency of ultraviolet radiation. The formation of industrial enterprises on terraces above the floodplain, from the first to the fifth, led to their actual encirclement of the residential area. Such enterprises as Kemerovskaya Regional Power Station, Kemerovskaya and Novokemerovskaya CHPPs, JSC "AZOT”, "TOKEM", JSC "Khimprom" are still the main air pollutants. However, nowadays, road transport is progressing among the main air pollutants, which is becoming one of the main environmental problems. While enterprises for the production and transmission of electricity, gas, steam and hot water, as well as the chemical industry, increase the degree of capturing pollutants, then the growth of road transport and its condition is poorly controlled.

\section{Materials and methods}

Attempts are made to solve the specified environmental problem related to the movement of transport by methods of regional land management in the city of Kemerovo. One of such events is the expansion of the carriageway of streets, such as Shakhterov Avenue, Lenin Avenue and others. This approach relieves traffic flows, thereby reducing emissions. In the near future, it is planned to build a new bridge and a bypass road, which will reduce the transit traffic flow. The road bypassing the city of Kemerovo will be built in stages:

- the first stage is the construction of a highway from the city of Topki to the Tom River;

- the second stage - construction of a bridge structure;

- the third stage - construction of a section from the bridge to the highway to Mariinsk.

Administrative position of the third work area: Kemerovo district, Kemerovo region. The studied site is located on the right bank of the Tom River between the Verkhotomskoe settlement and the village of Staraya Balakhonka (Fig. 1). In geomorphological terms, the site of the projected construction is located in the valley of the Tom River, covering its channel part, floodplain terraces and partly bluff slopes on both banks. In this section, in the alignment of the projected excavation, the valley is weakly terraced, a high floodplain stretches along the water's edge along both banks in narrow strips of 10-30 m wide, I and II terraces above the floodplain are developed, respectively, the first is on the right bank, the second is on the left bank of the Tom River. The absolute elevations of the relief of the Studied site range from $142.6 \mathrm{~m}$ to $193.6 \mathrm{~m}$. There are no industrial facilities in the excavation construction zone. There are residential settlements with medical, educational, cultural, entertainment and sports facilities in the immediate vicinity. Regarding engineering networks and supply pipelines, there are power lines, a regional highway (Kemerovo-Yashkino), and a number of dirt roads of secondary importance along the coastal zones of the Tom River. 


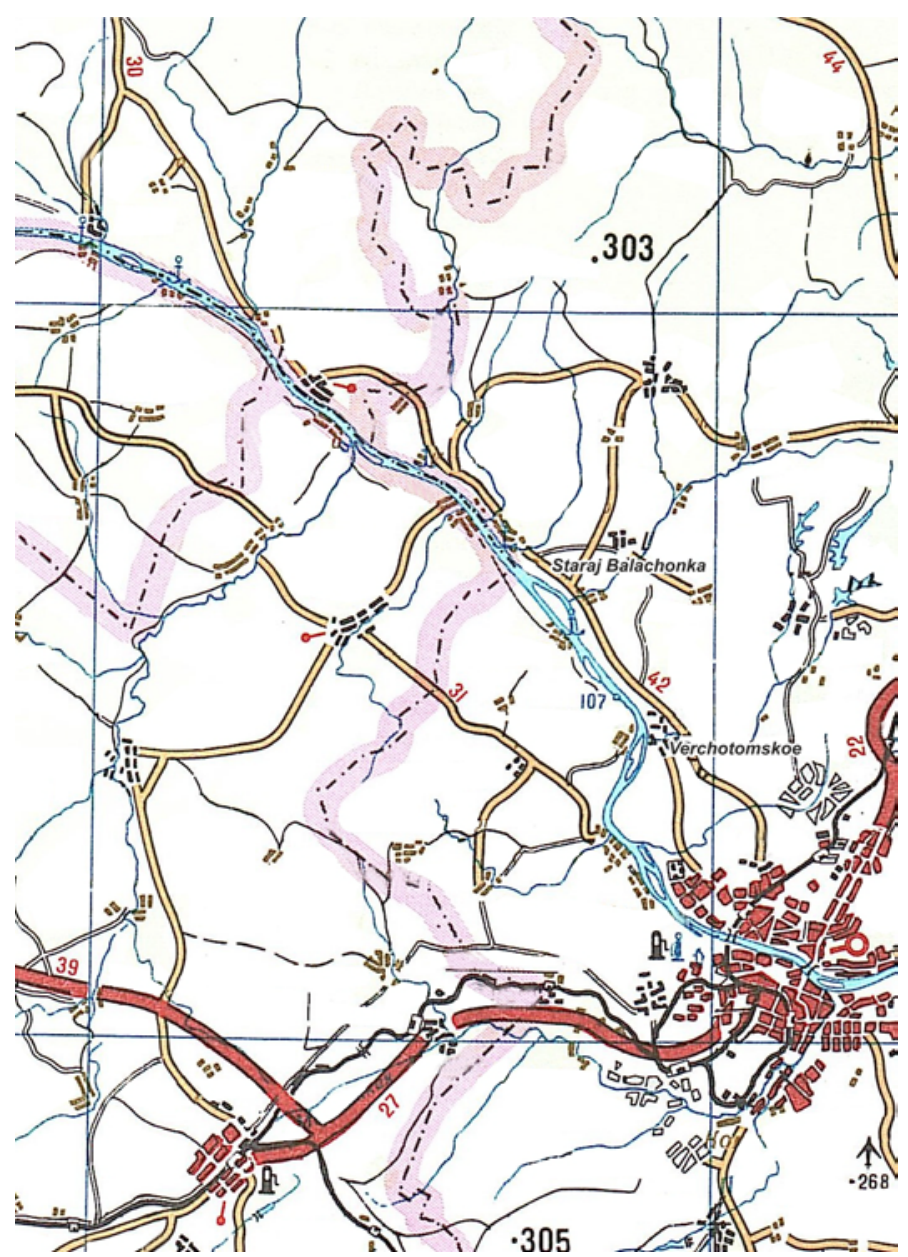

Fig. 1. Location of the study area.

Access to the survey area is possible at any time of the year by road. There are no discontinuities (faults). There are no mineral deposits. There are no manifestations of coal.

The rock base is represented by sandstones with interlayers of siltstones, mudstones and marbleized limestones exposed in the core of the northeastern fold within the terrigenouscarbonate strata of the lower section of the Carboniferous system. The bedrocks are overlain in the ravines by modern diluvial-proluvial deposits and Upper Quaternary deposits of slopes and watersheds: loess-like loams of the Elovskaya series, as well as crushed stone and block deposits of eluvial origin.

By these surveys, the lithological section has been studied to a depth of $35.0 \mathrm{~m}$ and is represented by the following deposits from the Lower Carboniferous to the Upper Quaternary - modern age:

- modern soils are loamy, highly porous, low-moisture, highly compressible, widespread throughout the excavation site, occurring from the surface, with an average thickness of 0.3-0.5 m;

- modern diluvial deposits: brown loam, semi-solid, light and heavy, silty, with an admixture of organic matter, distributed in the bottom and sides of the ravine crossing the northwestern corner of the excavation site, lie under the soil layer, thickness up to $2.7 \mathrm{~m}$; 
- Upper Quaternary diluvial loams, light brown, high-plastic, light, silty, distributed in the same way as overlying diluvial-proluvial loams, thickness reaches $1.5 \mathrm{~m}$;

- Lower Carboniferous - Quaternary eluvial formations (dispersed clastic weathering crust), represented by loam, crushed stone and block deposits with sandy loam filler, are distributed throughout the excavation area, lie under the soil layer and diluvial loam, the thickness varies from $1.7 \mathrm{~m}$ to $5.2 \mathrm{~m}$;

- Lower Carboniferous siltstones and gray and brownish-gray sandstones, polymictic, fine-grained, massive, fractured, weakly weathered, from medium strength to strong, distributed throughout the entire area, lie under the weathering crust, not exposed at full thickness, exposed thickness from $10.5 \mathrm{~m}$ to $30.5 \mathrm{~m}$. In hydrogeological terms, the work area is characterized by the presence of an aquifer of fractured-stratal waters of the bedrock fracture zone.

The supply of the aquifer is local, of an infiltration nature, and largely depends on the amount of precipitation and the intensity of the snow melting process. The water-bearing rocks in the described area are sandstones, the coefficient of water permeability is 200-300 $\mathrm{m}^{2} /$ day. At the time of the survey, the groundwater of the reservoir-fractured aquifer lay at a depth of $10.0 \mathrm{~m}$ or more, which corresponds to absolute elevations of $132.6 \mathrm{~m}$ and below. During the period of snowmelt and heavy rains, a short-term increase in the level by $1.5 \mathrm{~m}$ $2.0 \mathrm{~m}$ is possible. The lithological and genetic varieties of soils lying on the site, in accordance with the Russian State Standard GOST 20522-2012, are divided into the following geotechnical elements in terms of construction, physical and mechanical properties:

- modern soil is loamy, highly porous, low-moisture, highly compressible, spread over the entire excavation site, penetrated by all wells, lies from the surface, average thickness is 0.3-0.5 m, subject to excavation with subsequent use for the purpose of reclamation of disturbed lands;

- modern diluvial loam of semi-solid consistency, light and heavy, silty, with an admixture of organic matter, distributed locally in the bottom and sides of the ravine crossing the northwestern corner of the excavation site, penetrated by a well, lies under the soil, thickness up to $2.7 \mathrm{~m}$, according to laboratory data, natural moisture content is from 0.239 to $0.249 \mathrm{CU}$, density - from 1.88 to $1.90 \mathrm{~g} / \mathrm{cm}^{3}$, porosity coefficient - from 0.71 to $0.75 \mathrm{CU}$, water saturation coefficient - from 0.85 to $0.89 \mathrm{CU}$, indicators of mechanical properties matter: angle of internal friction - $21-23^{\circ}$, adhesion - 36-49 $\mathrm{kPa}$; deformation modulus E - 16.4 MPa;

- Upper Quaternary diluvial loam, high-plastic, light, silty, distributed locally in the bottom and sides of the ravine crossing the northwestern corner of the excavation site, penetrated by a well, thickness up to $1.5 \mathrm{~m}$, according to laboratory data, natural moisture ranges from 0.259 to $0.264 \mathrm{CU}$, density - from 1.93 to $1.95 \mathrm{~g} / \mathrm{cm}^{3}$, porosity coefficient from 0.74 to $0.76 \mathrm{CU}$, water saturation coefficient - from 0.92 to $0.96 \mathrm{CU}$, indicators of mechanical properties have the following values: angle of internal friction - $11-13^{\circ}$, adhesion - 12-14 kPa; deformation modulus E - 11.3 MPa;

- Lower Carboniferous-Quaternary eluvial loam, hard-semi-hard, widespread in the central and eastern parts of the excavation site, penetrated by wells, thickness varies from $1.0 \mathrm{~m}$ to $4.5 \mathrm{~m}$, according to laboratory data, natural moisture is from 0.145 to $0.275 \mathrm{CU}$, density - from 1.82 to $2.16 \mathrm{~g} / \mathrm{cm}^{3}$, the porosity coefficient is from 0.44 to $0.92 \mathrm{CU}$, the water saturation coefficient is from 0.82 to $0.98 \mathrm{CU}$, the indicators of mechanical properties are as follows: the angle of internal friction is $-24-31^{\circ}$, the adhesion is $47-123 \mathrm{kPa}$; deformation modulus E - 20.7 MPa;

- Lower Carboniferous-Quaternary eluvial soil, somewhere with loamy, sandy loam filler, dispersed clastic zone of the weathering crust, distributed locally in the bottom and sides of 
the ravine crossing the northwestern corner of the excavation site, penetrated by a well, thickness up to $1.7 \mathrm{~m}$, according to laboratory data, natural moisture content is from 0.181 to $0.185 \mathrm{CU}$, density is from 1.96 to $1.98 \mathrm{~g} / \mathrm{cm}^{3}$, porosity coefficient is from 0.61 to 0.64 $\mathrm{CU}$, water saturation coefficient is from 0.78 to $0.80 \mathrm{CU}$, design resistance is $4.0 \mathrm{kgf} / \mathrm{cm}^{2}$;

- Lower Carboniferous-Quaternary eluvial blocky soil of sandstones of polymictic composition (dispersed clastic weathering crust), distributed in the western part of the excavation site, penetrated by wells, lies in the upper part of the studied section, the thickness varies from $3.9 \mathrm{~m}$ to $5.2 \mathrm{~m}$, it is rocky soil, broken by a dense network of cracks for blocks of various sizes;

- Lower Carboniferous siltstone of low and medium strength, distributed in the central and eastern parts of the excavation site, lies under the weathering crust, penetrated by wells, with a thickness of $1.5 \mathrm{~m}$ to $3.6 \mathrm{~m}$, according to laboratory data, the ultimate strength for uniaxial compression at natural moisture content is from 9.3 up to $34.8 \mathrm{MPa}$, with water saturation from 1.1 to $10.7 \mathrm{MPa}$, respectively;

- lower Carboniferous gray sandstone, polymictic, fine-grained, massive, fractured, slightly weathered, from medium strength to strong, distributed throughout the entire area, lies under the weathering crust, not exposed at full thickness, exposed thickness from $6.9 \mathrm{~m}$ to $30.5 \mathrm{~m}$, according to laboratory data, natural humidity ranges from 0.110 to $0.126 \mathrm{CU}$, density - from 2.35 to $2.79 \mathrm{~g} / \mathrm{cm}^{3}$, uniaxial compressive strength at natural humidity from 16.25 to $103.81 \mathrm{MPa}$, with water saturation from 15.32 to $92.15 \mathrm{MPa}$, respectively.

\section{Results}

To study the geological and lithological structure of the section of the projected excavation, a complex of drilling operations was carried out. The distances between the workings and their number are taken in accordance with the requirements of the current regulatory documents, the technical characteristics of the designed structure, the expected geotechnical conditions, and the presence of natural and artificial obstacles. Drilling operations were carried out using URB 2A-2 self-propelled drilling rigs by a core drilling method with a diameter of $151 \mathrm{~mm}$, a run of penetration of $0.5 \mathrm{~m}$. Drilling of rocky soils and weathering crust was carried out by the core method with a diameter of up to $112 \mathrm{~mm}$ with blowing and washing, the run of penetration was $0.7 \mathrm{~m}$. Drilling was carried out with the sampling of monoliths and cores to determine the physical and mechanical properties of soils. Monoliths of cohesive soils were selected by crushing the soil carrier at an interval of 1.0 $2.0 \mathrm{~m}$. Soil sampling for visual description was carried out by taking point samples every $0.5 \mathrm{~m}$ of penetration from all wells. Field documentation, selection, marking and transportation of soil samples were carried out in accordance with the requirements of the current regulatory documents. At the end of the work, each well was closed (plugged) in accordance with the requirements of the regulatory documentation. The wells are located along the axis of the projected excavation and on the cross-sections to the axis. They were transferred from the topographic plan to the terrain by the geodetic service of Kuzbassdorfondproekt JSC. A set of laboratory works to study the physical and mechanical properties of soils was carried out in a specialized soil laboratory of Noostroy LLC. The studies were carried out according to approved methods, in accordance with the current regulatory documents in force. The samples were sent to the laboratory, where a "Conclusion on the state of measurements in the laboratory" was issued, confirming the presence in the soil laboratory of Noostroy LLC of the conditions necessary for measurements in the field of activity assigned to the laboratory. The certificate was issued by the Federal Budgetary Institution "State Regional Center for Standardization, Metrology and Testing" in the Kemerovo Region. The determination of the mechanical composition of 
soils was carried out by sieve and hydrometric methods. The determination of the corrosiveness of the soil was carried out using analyzers "AKAG (080728)", "Expert-001", "KFK-3". Laboratory studies of the physical and mechanical properties of rocky soils were carried out in the laboratory of the Kuzbass State Technical University. During the survey, measuring instruments were used that passed the planned state metrological verification. Office processing of materials was carried out in accordance with the requirements of the current regulatory documents.

\section{Discussion}

Office processing of the results of geotechnical surveys included a comprehensive processing of drilling operations, the results of laboratory determinations of physical and mechanical properties, and the results of field experimental work. The processing of the drilling results was carried out in two stages. At the first stage, as the work was carried out, preliminary geological-lithological columns of workings and geotechnical sections were built according to the field description of the wells. Based on the visual description of soils and a qualitative assessment of the lithological composition, a preliminary identification of geotechnical elements was carried out, which was refined based on the results of determining the strength and deformation properties of soils. Subsequently, they were corrected according to the results of laboratory determinations of the physical properties of soils. Based on the data of field and laboratory work, geotechnical sections were built with the allocation of geotechnical elements. The selection of geotechnical elements at the survey site was made using data from laboratory studies of the physical and mechanical properties of soils. Statistical processing of indicators of physical and mechanical properties of soils was carried out in accordance with the current regulatory documents, tables of standard and calculated characteristics of soils were compiled with confidence levels of 0.90 and 0.98 . The recommended modulus of deformation is given taking into account the coefficient corrected according to the results of plate load tests of soils. The location of the wells on the ground is indicated by the Customer in the terms of reference for the production of geotechnical surveys. Geophysical work by the VES method was carried out with low-frequency electrical exploration equipment of the ERP-5 "Berezka" type. Soundings were carried out with a symmetrical AMNB installation with a maximum separation of the AB supply line of 110 meters for VES-1-6 points, 80 meters for VES-8-41 points. Steel electrodes were used as feed electrodes, and copper pins $0.8 \mathrm{~m}$ long, which were driven to a depth of $0.3-0.5 \mathrm{~m}$, were used as receiving electrodes. The length of the $\mathrm{AB}$ spacing was determined by the need to clearly distinguish the reference horizon on the VES curve by at least three points. When passing from one measuring line to another, the VES curve was necessarily overlapped at two points. The direction of the spacing of the current electrodes $(\mathrm{AB})$ was chosen taking into account the geomorphological features of the work area. Whenever possible, intersections of the $\mathrm{AB}$ line with sharply inhomogeneous strata occurring near the surface and sharp relief forms were avoided. When arranging grounding, measures were taken to reduce grounding resistance by adding water to the current and receiving lines. To reduce the possible influence of leaks, the measuring line was located one or two meters from the current line. The amount of leakage was considered acceptable if the potential difference due to the leakage did not exceed $5 \%$ of the measured potential difference. AMTsG-100 batteries were used as power supplies for the $\mathrm{AB}$ line.

An accompanying measure to reduce the impact of emissions from road transport, provided for by the regional land management of Kemerovo, is the development of a 
system of green spaces. Nowadays, the area of public green spaces in the city is 618.1 hectares, the provision with public spaces is 11.6 square meters per inhabitant.

To accomplish this task, the following measures have been developed, including the organization of a green park zone:

- citywide significance: Pritomskaya, Komsomolsky and Valley of the Kamenushka River;

- urban in the eastern part of the Pioner settlement.

As a result of the proposed measures, it is planned to increase the area of public green spaces to 1,835 hectares, and the provision per inhabitant - 40.3 square meters.

\section{Conclusions}

Based on the performed studies, the following conclusions can be drawn.

1. Regional land management as a new method for solving environmental problems of the city of Kemerovo is useful for implementation both at the design stage of new buildings and at the reconstruction of old ones.

2. The direction of the regional zoning of urban lands in the city of Kemerovo should be focused on solving environmental problems.

3. Methods of regional land management in the city of Kemerovo have broad prospects of use for solving environmental problems, including:

- rational nature management;

- rational land use;

- comfortable living conditions for the population that meet the standards and requirements of the population for the quality of the environment;

- protection of the territory from dangerous natural and man-made impacts;

- sustainable social and economic development of the territory.

\section{References}

1. N.G. Ulusan, Proceedings of 3rd International Sustainable Buildings Symposium, 871879 (2017)

2. H.M. Shalaby, A. Sherif, H. Altan, Towards Sustainable Cities in Asia and the Middle East, 136-150 (2017)

3. M.G. Cantiani, Al. Betta, I. De Meo, Al. Paletto, S. Tamanini, F. Maino, SSPCR 2017: Smart and Sustainable Planning for Cities and Regions, 375-388 (2017)

4. M. Zhou, W. Bonenberg, Advances in Intelligent Systems and Computing 493, 125-136 (2016)

5. I. Nicolae, P. Sorina, Conference on Sustainable Energy: Nearly Zero Energy Communities (2017)

6. G. Kulkarni, D. Nilesh, Bh. Parag, P. Wasnik, K. Hambarde, P. Tamsekar, V. Kamble, V. Bahuguna, Proceedings of 2nd International Conference on Intelligent Computing and Applications (2015)

7. M.S.P.M. Sirirwardane, Ja. Gunatilake, S. Sivanandarajah, Geostatistical and Geospatial Approaches for the Characterization of Natural Resources in the Environment (2015)

8. X.-M. Kuang, J. Chen, Ch.-F Sun, Low-carbon City and Newtype Urbanization (2015) 
9. E. Moir, T. Moonen, G. Clark, Catapult Future Cities, Foresight (United Kingdom, 2014)

10. K.S. Chandrasekar, B. Bajracharya, D. O'Hare, Bond University Gold Coast 20 (2016)

11. T. Rehackova, E. Pauditsova, Acta Environmentalica Universitatis Comenianae 15, 26-38 (2007)

12. M. Jankevica, Research for Rural Development 2, 134-140 (2012)

13. M. Aliman, A. Yustesia, E. Barlian, N. Syah, Sumatra Journal of Disaster, Geography and Geography Education 1(2), 140-146 (2017)

14. M.G. Cantiani, Al. Betta, I. De Meo, Al. Paletto, S. Tamanini, F. Maino, SSPCR 2017: Smart and Sustainable Planning for Cities and Regions, 375-388 (2017)

15. C. Zhenqi, L. Weichi, Advances in Intelligent Systems and Computing 454, 509-520 (2015)

16. J. Zhao, Zh. Fang and Ya Zhao, Green Intelligent Transportation Systems, 751762 (2016)

17. A. Solovitskiy, O. Brel, N. Nikulin, E. Nastavko, T. Meser, The Second International Innovative Mining Symposium (2017) http://doi.org/10.1051/e3sconf/ 20172102012 